Anuario de

Derechos Humanos 2005 


\title{
Reseña de la Jurisprudencia de la Corte Interamericana de Derechos Humanos (2004) Relevante para los Derechos Humanos en Chile
}

\author{
Claudio Nash R.*
}

\section{Antecedentes Generales}

L a Corte Interamericana de Derechos Humanos (en adelante la "Corte") fue establecida en el sistema interamericano por la Convención Americana sobre Derechos Humanos (en adelante "CADH" o "Convención" o "Convención Americana" o "Pacto de San José" $)^{1}$. Sus funciones son dos: a) resolver los casos contenciosos sobre una presunta violación a la Convención de un Estado parte, y b) emitir opiniones consultivas.

Conforme lo preceptuado en el artículo 63 de la Convención, la Corte establecerá si ha habido una violación de alguno de los derechos o libertades consagrados en la Convención Americana; además, determinará la forma en que el Estado debe restituir la situación al estado anterior a la comisión del ilícito y, en caso de que esto no sea posible, determinará la forma en que se reparará el mal causado. En el artículo 68.1 de la Convención las partes se comprometen a cumplir con las decisiones de la Corte en todo caso en que intervengan.

Durante el año 2004 la Corte dictó 9 sentencias definitivas.

Por su parte, el artículo 64 de la Convención permite a los Estados miembros de la Organización de Estados Americanos ("OEA") y, en lo que les compete, a los órganos enumerados en el capítulo $X$ de la Carta de la OEA, consultar a la Corte acerca de la interpretación de la Convención de otros tratados concernientes a la protección de los derechos humanos. Permite también a los Estados miembros solicitar una opinión sobre la compatibilidad de cualquiera de sus leyes internas con los instrumentos internacionales mencionados.

Durante el año 2004 la Corte no emitió ninguna opinión consultiva.

En este artículo vamos a reseñar algunas de las materias resueltas por la Corte que presenten relevancia para Chile, ya sea por los temas tratados y/o por las consecuencias que pueden tener estas materias para nuestro país si quiere estar en armonía con sus obligaciones internacionales.

De esta forma, nos referiremos a dos situaciones generales que son de especial importancia para Chile: por una parte, la situación de las

* Coordinador del Centro de Derechos Humanos, Facultad de Derecho, Universidad de Chile.

1 La Convención Americana sobre Derechos Humanos se adoptó en 1969 durante la Conferencia Especializada de Derechos Humanos, realizada en San José, Costa Rica.
Este comentario, junto con los documentos a que se refiere, están disponible en formato digital en www.anuariocdh.uchile.cl 
2 Caso Instituto de Reeducación del Menor, seguido en contra de Paraguay, relativo a las condiciones penitenciarias en una cárcel para menores de edad. En ella se produjeron una serie de incendios que costaron la vida de algunos de los niños privados de libertad en dicho centro. personas privadas de libertad en nuestros sistemas penitenciarios $y$, por la otra, la situación de los niños y niñas, incluidos aquellos que se encuentran privados de libertad. También reseñaremos algunas sentencias de la Corte que se han referido a dos temas que han estado, o bien, estarán, instalados en nuestro debate. Nos referimos a los alcances de la libertad de pensamiento y expresión, en particular, en el contexto de procesos electorales y/o de control de la actividad pública, y al derecho a un recurso ante una segunda instancia en los casos procesales penales. Esta última, sin duda, será una materia de análisis en nuestro país atendido que la reforma procesal penal contempla un mecanismo de revisión de las sentencias que no parece cumplir estrictamente con los estándares internacionales.

\section{Situación en las Cárceles}

\section{Obligaciones del Estado}

La privación de libertad es una medida legítima que puede adoptar el Estado, en la medida que cumpla con ciertas condiciones, tanto en lo que dice relación con su dictación, como con la finalidad que persiga y con la forma en la que se implemente.

De conformidad con lo preceptuado en el artículo 7.5 de la Convención, la prisión preventiva sólo es legítima en la medida que ésta sea aplicada durante un plazo razonable, ya que la libertad sólo puede estar condicionada a garantías que aseguren su comparecencia en el juicio. Respecto de aquellas personas que han sido condenadas, la Convención señala que las penas privativas de la libertad tendrán como finalidad esencial la reforma y la readaptación social de los condenados (artículo 5.6 $\mathrm{CADH}$ ). Si bien esta es una realidad muy lejana en el sistema carcelario latinoamericano, es claro cuál es el sentido que debe darse a toda reforma en el sistema y hacia dónde debieran apuntar todas las medidas que se tomen en el ámbito carcelario.

Las personas privadas de libertad son titulares de todos y cada uno de los derechos establecidos en la Convención, sin perjuicio de que el goce de alguno de ellos esté temporalmente restringido. La restricción legítima de la libertad no implica que la persona pierda el derecho a gozar y ejercer otros derechos y libertades fundamentales, sin perjuicio que algunos de ellos se vean indirectamente afectados. Es una obligación del Estado garantizar que toda norma que restrinja el goce y ejercicio de los derechos humanos debe ser conducente y proporcional para conseguir el objetivo que le es propio (artículo $30 \mathrm{CADH}$ ) y será obligación de las autoridades encargadas de su implementación limitar al máximo los efectos, que quizás pudiéramos Ilamar colaterales, respecto de las personas en situación de privación de libertad.

\section{Jurisprudencia Relevante}

En la sentencia del Caso Instituto de Reeducación del Menor $^{2}$ la Corte plantea la vinculación entre las condiciones de privación de libertad 
con las obligaciones del artículo 5 de la CADH. A su juicio, si estas condiciones de vida material no satisfacen ciertos estándares mínimos, pueden afectar la "salud mental" de las personas recluidas y, de esta forma, provocar responsabilidad internacional del Estado por afectación a la integridad psíquica de las personas ${ }^{3}$. En el Caso Tibi ${ }^{4}$, la Corte reitera el razonamiento y señala que la situación personal de las personas privadas de libertad se enmarca en el ámbito del artículo 5.2 de la CADH y, por tanto, se consagra el derecho de toda persona "a vivir en situación de detención compatible con su dignidad personal $^{\prime \prime}$, derecho que se encuentra íntimamente ligado con las condiciones de vida del detenido ${ }^{6}$. El Estado, en atención a su condición de garante de las condiciones de vida de las personas privadas de libertad y como responsable final de los establecimientos de detención, debe garantizar a los reclusos la existencia de condiciones que dejen a salvo sus derechos ${ }^{7}$.

Formuladas estas consideraciones generales, corresponde analizar ciertas cuestiones particulares que la Corte entra a conocer en sus sentencias, cuales son, la prohibición de ciertos castigos, la separación entre procesados y condenados, el derecho a atención médica y la obligación de investigar en caso de denuncia de malos tratos o torturas sufridas por los detenidos.

La Corte reitera en el Caso Instituto de Reeducación del Menor la prohibición no solo de cierta clase de castigos, como el aislamiento, maltrato e incomunicaciones, sino que sostiene que constituye una violación del artículo 5 el solo hecho de verse bajo la amenaza de sufrir dichas formas de castigo; ampliando de esta forma los medios a través de los cuales el Estado puede incurrir en responsabilidad ${ }^{8}$.

En relación con la obligación establecida en el artículo 5.4 del Pacto de San José, la Corte señala en el Caso Tibi, que "[en el caso] no había un sistema de clasificación de los detenidos en el centro penitenciario en donde estuvo recluido el señor Tibi y que por esta razón se vio en la necesidad de convivir con sentenciados y quedó expuesto a mayor violencia" y por tanto, la "falta de separación de reclusos descrita" implica una violación del artículo 5.4 de la CADH ${ }^{9}$.

Respecto de la obligación del Estado de brindar atención médica a los detenidos, la Corte establece en la sentencia del Caso Tibi, algunas particularidades de este derecho. Entiende que conforme con lo preceptuado en el artículo 5 de la $\mathrm{CADH}$, "el Estado tiene el deber de proporcionar a los detenidos revisión médica regular y atención y tratamiento adecuados cuando así se requiera". De la misma forma, el Estado debe garantizar que "los detenidos sean atendidos por un facultativo elegido por ellos mismos o por quienes ejercen su representación o custodia legal" ${ }^{\prime 10}$. En su análisis, la Corte va más allá y señala expresamente que una deficiente atención médica de un detenido, en caso de requerir de un "tratamiento o atención médica adecuada y oportuna", implica una violación del artículo 5 de la $\mathrm{CADH}^{11}$.
3 Caso Instituto de Reeducación del Menor, párr. 168

4 Caso Tibi, seguido en contra de Ecuador por la detención de un ciudadano francés acusado de narcotráfico.

5 Caso Tibi, párr. 150. En el mismo sentido ver Caso Bulacio, párr. 126; y Caso Cantoral Benavides, párr. 87.

6 Caso Tibi, párr. 150. Ver en este sentido, Caso Cantoral Benavides, párrs. 85 al 89; y Caso Loayza Tamayo, párr. 58.

7 Caso Tibi, párr. 150. En el mismo sentido ver Caso Lori Berenson, párr. 102; Caso Bulacio, párr. 126.

8 Caso Instituto de Reeducación del Menor, párr. 167.

9 Caso Tibi, párr. 158.

10 Ibídem, párr. 156. En el mismo sentido, ver Caso Bulacio, párr. 131.

11 Caso Tibi, párr. 157. 
12 Ibídem, párr. 159.

13 Idem.

${ }^{14}$ Caso Villagrán Morales y otros; Condición Jurídica y Derechos Humanos del Niño (OC-17).

15 Caso Villagrán Morales y otros, párr. 194; Caso de los Hermanos Gómez Paquiyauri, párr. 166.

16 Caso Villagrán Morales y otros, párr. 196.

17 Instituto de Rehabilitación, párr. 147. Ver en el mismo sentido, Condición Jurídica y Derechos Humanos del Niño, párr. 54; y Caso de los Hermanos Gómez Paquiyauri, párr. 164.
Finalmente, la Corte se refiere a la obligación del Estado de investigar aquellos casos en que pueda estarse ante una situación de malos tratos o de tortura. Funda dicha obligación en el artículo 1.1, en concordancia con el artículo 5, ambos de la CADH, ya que "el Estado tiene el deber de iniciar de oficio e inmediatamente una investigación efectiva que permita identificar, juzgar y sancionar a los responsables, cuando existe denuncia o razón fundada para creer que se ha cometido un acto de tortura en violación del artículo 5 de la Convención Americana"12. Al efecto, el solo hecho de que la persona privada de libertad presente lesiones en el período en que ha estado bajo custodia directa del Estado es "motivo suficiente para que las autoridades competentes iniciaran, de oficio, una investigación sobre lo ocurrido a éste" ${ }^{\prime 13}$.

\section{Situación de los Niños}

\section{Obligaciones del Estado}

La Corte Interamericana de Derechos Humanos, ha ido estableciendo ciertos parámetros respecto de los derechos de los niños a la luz de la $\mathrm{CADH}^{14}$. En primer lugar, ha quedado asentada la idea de que tanto la Convención Americana como la Convención sobre los Derechos del Niño forman parte de un muy comprensivo corpus juris internacional de protección de los niños que debe servir a la Corte para fijar el contenido y alcance de la disposición general definida en el artículo 19 de la Convención Americana ${ }^{15}$. En segundo lugar, la Corte ha señalado los alcances de las "medidas de protección" a que alude el artículo 19 de la Convención Americana. Entre ellas merecen ser destacadas las referentes a la no discriminación, a la asistencia especial a los niños privados de su medio familiar, a la garantía de la supervivencia y el desarrollo del niño, al derecho a un nivel de vida adecuado y a la reinserción social de todo niño víctima de abandono o explotación ${ }^{16}$.

Si bien estos eran avances interesantes, aún estaba pendiente concretar algunos de los aspectos relativos a la forma correcta de interpretar el artículo 19 de la CADH, que la sentencia dictada en el caso Instituto de Reeducación del Menor aborda en mayor profundidad.

\section{Jurisprudencia Relevante}

\section{A. OBLIGACIONES GENERALES RESPECTO DE LA INFANCIA}

Primeramente, la Corte formula una declaración general, señalando que los niños son titulares de todos los derechos humanos, al igual que los adultos, y que el artículo 19 de la CADH debe entenderse "como un derecho adicional, complementario, que el tratado establece para seres que por su desarrollo físico y emocional necesitan de protección especial"17.

Metodológicamente es interesante el Caso Instituto de Reeducación del Menor en dos sentidos. Primero, porque en su análisis de los derechos violados por el Estado de Paraguay, la Corte utilizó el artículo 
19 precitado para analizar cada uno de los derechos en estudio, particularmente, los artículos 4, 5 y 7 de la misma Convención ${ }^{18}$. Nos parece que esta es la forma correcta de leer el artículo 19, en cuanto éste lo que hace es fijar un plus respecto de las obligaciones del Estado, en cuanto a la necesidad de adoptar medidas especiales que protejan los derechos consagrados en el propio texto de la Convención. Segundo, porque usó para fijar el contenido y alcance de las obligaciones del Estado una serie de instrumentos internacionales de que era parte el Estado demandado y que a través de una interpretación integral le permite una lectura amplia de las obligaciones respecto de los niños que le lleva a sostener que ellos, bajo la Convención Americana sobre Derechos Humanos, son titulares de derechos tanto de naturaleza civil y política, como económica, social y cultural, en particular, en lo que dice relación con su derecho a la vida y a la integridad personal ${ }^{19}$.

Un tema relevante en el sentencia que estamos comentando es el relativo a las obligaciones que tienen los Estados que han ratificado la $\mathrm{CADH}$ de adecuar su legislación en materia de justicia de menores de edad, todo ello en conformidad con lo preceptuado en los artículos 2 y 8.1 de la Convención Americana, en relación con los artículos 19 y 1.1 de la misma. Las obligaciones que los Estados adoptan en materia de derechos humanos comprenden la obligación de adecuar su legislación ${ }^{20}$ y, en el caso particular de la justicia para menores de 18 años, implica adecuar los estándares procesales penales a las obligaciones establecidas tanto en la propia CADH como en la Convención sobre los Derechos del Niño.

Sobre el alcance de las garantías consagradas en el artículo 8 de la Convención se reconoce que éstas corresponden a todas las personas por igual, y además, el artículo 19 de la misma obliga al Estado a consagrar estos derechos en todo proceso, ya sea administrativo o judicial, en el que se discuta algún derecho de un niño, tomando las medidas necesarias para su efectividad ${ }^{21}$.

Otra cuestión relevante, en materia de proceso penal que afecta a los menores de 18 años, es su privación de libertad. A juicio de la Corte, la regla de la prisión preventiva se debe aplicar con mayor rigurosidad, toda vez que la norma debe ser la aplicación de medidas sustitutorias de la prisión preventiva. La aplicación de medidas sustitutorias tiene por finalidad asegurar que los niños sean tratados de manera adecuada y proporcional a sus circunstancias y a la infracción investigada ${ }^{22}$. En el caso que la medida de privación de libertad sea procedente, ésta debe aplicarse siempre durante el plazo más breve posible, tal como lo establece el artículo 37.b) de la Convención sobre los Derechos del Niño ${ }^{23}$.

\section{B. SITUACIÓN DE LOS NIÑOS PRIVADOS DE LIBERTAD}

Respecto de las obligaciones especiales que tiene el Estado para con los niños privados de libertad, la Corte realiza su análisis a la luz del derecho a la vida y a la integridad personal, debidamente complementado con el artículo 19 de la CADH. En cuanto al derecho a la vida la Corte señala
18 Caso Instituto de Reeducación del Menor, párr. 148.

19 Ibídem, párr. 149.

20 Ibídem, párrs. 205-206. En el mismo sentido, ver Caso "Cinco Pensionistas", párr. 165; Caso Baena Ricardo y otros, párr. 180; Caso Cantoral Benavides, párr. 178.

21 Caso Instituto de Reeducación del Menor, párr. 229. En el mismo sentido ver, Condición Jurídica y Derechos Humanos del Niño, párr. 95 y 98.

22 Caso Instituto de Reeducación del Menor, párr. 230.

23 Ibídem, párr. 231. 
24 Ibídem, párr. 160. En el mismo sentido ver Caso de los Hermanos Gómez Paquiyauri, párrs. 124, 163-164, y 171; Caso Bulacio, párrs. 126 y 134; y Caso de los "Niños de la Calle", párrs. 146 y 191; Condición Jurídica y Derechos Humanos del Niño, párrs. 56 y 60.

25 Caso Instituto de Reeducación del Menor, párr. 160.

26 Ibídem, párrs. 161, 173 y 174. Ver en el mismo sentido, Condición Jurídica y Derechos Humanos del Niño, párrs. 80-81, 84, y 86-88; Caso de los "Niños de la Calle", párr. 196.

27 Caso Instituto de Reeducación del Menor, párr. 176.

28 Ibídem, párr. 172.

29 Idem, párr. 172.

30 Ibídem, párr. 175.

31 Ibídem, párr. 178.

32 Ibídem, párr. 179. que: "cuando el Estado se encuentra en presencia de niños privados de libertad, tiene, además de las obligaciones señaladas para toda persona, una obligación adicional establecida en el artículo 19 de la Convención Americana. Por una parte, debe asumir su posición especial de garante con mayor cuidado y responsabilidad, y debe tomar medidas especiales orientadas en el principio del interés superior del niño ${ }^{\prime 24}$. Pero la Corte va más allá y vincula el derecho a la vida con la preocupación que el Estado debe desarrollar respecto de las "circunstancias de la vida que llevará mientras se mantenga privado de libertad" ${ }^{\prime 25}$. Vincula la Corte estas "circunstancias de la vida" con los artículos 6 y 27 de la Convención sobre los Derechos del Niño que incluyen, en el derecho a la vida, la obligación del Estado de garantizar "en la máxima medida posible la supervivencia y el desarrollo del niño".

De esta forma, el Estado tiene, respecto de niños privados de libertad y, por lo tanto, bajo su custodia, la obligación de, inter alia, proveerlos de asistencia de salud y de educación, para así asegurarse de que la detención a la que los niños están sujetos no destruirá sus proyectos de vida ${ }^{26}$. De ahí que la Corte haya vinculado la idea de "vida digna" con las obligaciones positivas que debe adoptar el Estado para garantizar efectivamente dicho derecho ${ }^{27}$. El fundamento de estas medidas especiales está dado en la circunstancia "que los niños se encuentran en una etapa crucial de su desarrollo físico, mental, espiritual, moral, psicológico y social que impactará de una u otra forma su proyecto de vida" 28 .

En cuanto a las obligaciones respecto de la integridad personal, la Corte hace especial referencia al artículo 5.5 de la Convención Americana que obliga a los Estados a mantener a los niños privados de libertad separados de los adultos ${ }^{29}$. No actuar de esta forma, exponía a los niños a circunstancias que son altamente perjudiciales para su desarrollo y los hace vulnerables ante terceros que, por su calidad de adultos, pueden abusar de su superioridad ${ }^{30}$.

Finalmente, parece importante llamar la atención respecto a las consideraciones que ha tenido la Corte a la vista al momento de determinar la responsabilidad del Estado por su falta de previsión en el incendio que se produjo en la cárcel del Estado demandado y que motivó la presentación del caso. En primer lugar, se establece que el Estado debe tomar medidas suficientes "para enfrentar la posibilidad de un incendio" y contar con "todas las medidas de seguridad, evacuación y emergencia necesarias para un evento de esta naturaleza" ${ }^{31}$. Esta falta de prevención, por los efectos que produjo en la muerte de los niños privados de libertad, "equivale a una negligencia grave que lo hace responsable de la violación del artículo 4.1 de la Convención Americana, en relación con el artículo 1.1 de la misma, y respecto de los niños, leído también a la luz del artículo 19 de la misma Convención, en perjuicio de los internos..." ${ }^{32}$. 


\section{Libertad de Expresión}

\section{Obligaciones del Estado}

Respecto del derecho a la libertad de pensamiento y expresión, contemplado en el artículo 13 de la CADH, la Corte ha establecido una sólida y uniforme doctrina. Sobre el contenido del derecho ha destacado que "quienes están bajo la protección de la Convención tienen no sólo el derecho y la libertad de expresar su propio pensamiento, sino también el derecho y la libertad de buscar, recibir y difundir informaciones e ideas de toda índole ${ }^{\prime \prime 33}$.

De esta forma, la Corte ha distinguido una dimensión individual y una social. La dimensión individual comprende el derecho a hablar o escribir, así como el derecho a utilizar cualquier medio apropiado para difundir el pensamiento y hacerlo llegar al mayor número de destinatarios; cualquier restricción al derecho a divulgar opiniones, implica un límite al derecho a expresarse libremente ${ }^{34}$. La dimensión social, por su parte, comprende el derecho a tratar de comunicar a otras personas los puntos de vista personales, pero implica también el derecho de todos a conocer opiniones, relatos y noticias; en este sentido, según la Corte, para los ciudadanos es igualmente importante difundir las propias ideas, como conocer las ideas e informaciones de otros ${ }^{35}$.

A juicio de la Corte "ambas dimensiones poseen igual importancia y deben ser garantizadas en forma simultánea para dar efectividad total al derecho a la libertad de pensamiento y de expresión en los términos previstos por el artículo 13 de la Convención" ${ }^{\prime 36}$.

En cuanto a la relevancia de la libertad de pensamiento y expresión en una sociedad democrática, la Corte ha señalado, en concordancia con la jurisprudencia comparada, que "[S] in una efectiva libertad de expresión, materializada en todos sus términos, la democracia se desvanece, el pluralismo y la tolerancia empiezan a quebrantarse, los mecanismos de control y denuncia ciudadana se comienzan a tornar inoperantes $y$, en definitiva, se crea el campo fértil para que sistemas autoritarios se arraiguen en la sociedad"137.

No podemos dejar de mencionar un fallo contra Chile, referente a medidas de censura previa. En él, la Corte ha señalado que "el artículo 13.4 de la Convención establece una excepción a la censura previa, ya que la permite en el caso de los espectáculos públicos pero únicamente con el fin de regular el acceso a ellos, para la protección moral de la infancia y la adolescencia. En todos los demás casos, cualquier medida preventiva implica el menoscabo a la libertad de pensamiento y de expresión ${ }^{\prime \prime 38}$.

\section{Jurisprudencia Relevante}

En dos sentencias dictadas el 2004 la Corte ha tratado algunas cuestiones novedosas y de gran relevancia para nuestra región. Las trataremos en el siguiente orden: el rol de los medios de comunicación
33 Caso Ricardo Canese, párr. 77. En el mismo sentido, Caso Herrera Ulloa, párr. 108; Caso "La Última Tentación de Cristo", párr. 64; La colegiación obligatoria de periodistas, párr. 30 .

34 Caso Ricardo Canese, párr. 78; Caso Herrera Ulloa, párr. 109; Caso "La Última Tentación de Cristo", párr. 65.

35 Caso Ricardo Canese, párr. 79; Caso Herrera Ulloa, párr. 110; Caso "La Última Tentación de Cristo", párr. 66.

36 Caso Ricardo Canese, párr. 80; Caso Herrera Ulloa, párr. 111; Caso "La Última Tentación de Cristo", párr. 67.

37 Caso Ricardo Canese., párr. 87; Caso Herrera Ulloa, párr. 116.

${ }^{38}$ Caso "La Última Tentación de Cristo", párr. 70. Esta sentencia se tradujo en un proceso de adecuación de la legislación interna chilena en materia de libertad de expresión que culminó con una reforma constitucional. 
${ }^{39}$ Caso Herrera Ulloa, seguido en contra de Costa Rica por la condena a un periodista por reproducir informaciones aparecidas en Europa respecto de las actuaciones de un funcionario del Estado que comprometía posibles actos de corrupción.

40 Caso Herrera Ulloa, párr. 117. En el mismo sentido, ver Caso Ivcher Bronstein, párr. 149.

41 Caso Herrera Ulloa, párr. 117.

42 Ibídem, párr. 118. En el mismo sentido ver $L a$ colegiación obligatoria de periodistas, párr. 71.

43 Caso Herrera Ulloa, párr. 118. En el mismo sentido, ver La colegiación obligatoria de periodistas, párrs. 72 y 74 .

${ }^{44}$ Caso Herrera Ulloa, párr. 119.

${ }^{45}$ Caso Canese, seguido en contra de Paraguay, por la condena dictada en contra de un candidato a la presidencia por las denuncias formuladas respecto de otro candidato por presuntos actos de corrupción, todo en el marco de un proceso presidencial.

46 Caso Ricardo Canese, párr. 88. En un sentido similar se ha pronunciado la Corte Europea de Derechos Humanos en el Case of Incal v. Turkey, judgment of 9 June, 1998, Reports 1998-IV, para. 46 (citado en Caso Ricardo Canese, párr. 89). y periodismo en relación con la libertad de pensamiento y expresión; la importancia de la libertad de pensamiento y expresión en el marco de una campaña electoral y, finalmente, algunos alcances sobre las restricciones a la libertad de pensamiento y expresión.

\section{A. EL ROL DE LOS MEDIOS DE COMUNICACIÓN Y PERIODISMO EN RELACIÓN CON LA LIBERTAD DE PENSAMIENTO Y EXPRESIÓN}

Respecto de los medios de comunicación social, en la sentencia del Caso Herrera Ulloa ${ }^{39}$, la Corte formula un doble alcance; por una parte, destaca su "rol esencial como vehículos para el ejercicio de la dimensión social de la libertad de expresión en una sociedad democrática, razón por la cual es indispensable que recojan las más diversas informaciones y opiniones" ${ }^{40} y$, por otra, les asigna responsabilidad en el sentido que como "instrumentos esenciales de la libertad de pensamiento y de expresión, deben ejercer con responsabilidad la función social que desarrollan" ${ }^{41}$.

Concretamente, en referencia al periodismo, la Corte señala que éste es la "manifestación primaria y principal de esta libertad y, por esa razón, no puede concebirse meramente como la prestación de un servicio al público a través de la aplicación de los conocimientos o la capacitación adquiridos en la universidad" ${ }^{\prime 2}$. Siendo los periodistas quienes ejercen profesionalmente la comunicación social, el ejercicio del periodismo "requiere que una persona se involucre responsablemente en actividades que están definidas o encerradas en la libertad de expresión garantizada en la Convención" ${ }^{\prime 3}$.

En consideración al rol que los periodistas juegan en la sociedad y al importante papel que cumplen para el goce de la libertad y el debate público, la Corte sostiene que "es fundamental que los periodistas que laboran en los medios de comunicación gocen de la protección y de la independencia necesarias para realizar sus funciones a cabalidad" ${ }^{\prime 4}$.

\section{B. LIBERTAD DE PENSAMIENTO Y EXPRESIÓN EN EL MARCO DE UNA CAMPAÑA ELECTORAL}

En el Caso Canese ${ }^{45}$, la Corte sostiene que "en el marco de una campaña electoral, la libertad de pensamiento y de expresión en sus dos dimensiones constituye un bastión fundamental para el debate durante el proceso electoral". Para sostener esto la Corte tiene en consideración los siguientes elementos: a) la formación de la opinión pública de los electores, b) el fortalecimiento de la contienda política entre los distintos candidatos y partidos que participan en los comicios y c) el análisis de las plataformas políticas planteadas por los distintos candidatos, lo cual permite una mayor transparencia y fiscalización de las futuras autoridades y de su gestión ${ }^{46}$.

La Corte desarrolla los alcances del debate democrático en el contexto de la formación de la opinión ciudadana en un proceso electoral en los siguientes términos: 
"[E]l debate democrático implica que se permita la circulación libre de ideas e información respecto de los candidatos y sus partidos políticos por parte de los medios de comunicación, de los propios candidatos y de cualquier persona que desee expresar su opinión o brindar información. Es preciso que todos puedan cuestionar e indagar sobre la capacidad e idoneidad de los candidatos, así como disentir y confrontar sus propuestas, ideas y opiniones de manera que los electores puedan formar su criterio para votar" ${ }^{\prime \prime}$.

Ahora, la Corte, a efectos de poder analizar la naturaleza de las opiniones que se vierten en el proceso electoral, tiene en consideración la distinción formulada en el Caso Herrera Ulloa, respecto de opiniones privadas y las opiniones de interés público ${ }^{48}$, calificando aquellas que dicen relación con actos de corrupción como opiniones que "atañen a asuntos de interés público" $"$ "

Con estos elementos a la vista, la Corte sostiene que los medios de comunicación que recogen las críticas de un candidato a la presidencia respecto de un contendor, en la medida que

"[a] estaba ejercitando su derecho a la libertad de pensamiento y de expresión en el marco de una contienda electoral, [b] en relación con una figura pública como es un candidato presidencial, [c] sobre asuntos de interés público, al cuestionar la capacidad e idoneidad de un candidato para asumir la Presidencia de la República"150, no hicieron sino contribuir "a que el electorado cuente con mayor información y diferentes criterios previo a la toma de decisiones ${ }^{\prime \prime 51}$.

\section{ALGUNOS ALCANCES SOBRE LAS RESTRICCIONES A LA LIBERTAD DE PENSAMIENTO Y EXPRESIÓN}

La Corte destaca en su jurisprudencia que "el derecho a la libertad de expresión no es un derecho absoluto; este puede ser objeto de restricciones", una de las cuales puede ser la aplicación de responsabilidades ulteriores por el ejercicio abusivo de este derecho. Para que sea procedente esta restricción deben concurrir ciertos requisitos

"[las restricciones] 1) deben estar expresamente fijadas por la ley; 2) deben estar destinadas a proteger ya sea los derechos o la reputación de los demás, o la protección de la seguridad nacional, el orden público o la salud o moral pública; y 3) deben ser necesarias en una sociedad democrática", ello con el objeto de que esta restricción no se transforme en un mecanismo directo o indirecto de censura previa ${ }^{52}$.

Sobre la "necesidad", la Corte ha establecido que la adopción de las medidas restrictivas "dependerá de que estén orientadas a satisfacer un interés público imperativo. Entre varias opciones para alcanzar ese objetivo debe escogerse aquélla que restrinja en menor escala el derecho protegido" ${ }^{53}$. En el caso concreto de la libertad de expresión, "la restricción debe ser proporcionada al interés que la justifica y ajustarse estrechamente al logro de ese objetivo, interfiriendo en la menor medida posible en el efectivo ejercicio del derecho a la libertad de expresión" ${ }^{\prime 24}$.

Al momento de analizar las restricciones compatibles con la Convención, la Corte vuelve sobre un tema relevante, cual es, "distinguir
47 Caso Ricardo Canese, párr. 90.

48 Caso Herrera Ulloa, párr. 125.

${ }^{49}$ Caso Ricardo Canese, párr. 92.

50 Ibídem, párr. 94.

51 Idem.

52 Caso Herrera Ulloa, párr. 120.

53 Caso Ricardo Canese, párr. 96; Caso Herrera Ulloa, párr. 121 y 123; La colegiación obligatoria de periodistas, párr. 46.

54 La colegiación obligatoria de periodistas, párr. 46, citado en Caso Herrera Ulloa, párr. 121. 
55 Caso Herrera Ulloa, párr. 125. En esta materia la Corte sigue los criterios establecidos por la Corte Europea en Case of Dichand and others $v$. Austria, Judgment of 26 February, 2002, para. 39; Case of Lingens v. Austria, Judgment of 8 July, 1986, Series A no. 103, para. 42.

56 Caso Herrera Ulloa, párr. 127; Caso Ricardo Canese, párr. 97. Ver en el mismo sentido, Caso Ivcher Bronstein, párr. 155. También puede consultarse en el sistema europeo, Case of Feldek v. Slovakia, Judgment of 12 July, 2001, para. 83; Case of Sürek and Özdemir v. Turkey, Judgment of 8 July, 1999, para. 60.

57 Caso Ricardo Canese, párr. 101.

58 Caso Ricardo Canese, párr. 100; Caso Herrera Ulloa, párr. 128.

59 Corte Europea de Derechos Humanos, Case of Dichand and others $v$. Austria, Judgment of 26 February, 2002, para. 39; Case of Lingens v. Austria, Judgment of 8 July, 1986, Series A no. 103, para. 42.

60 Caso Ricardo Canese, párr. 103; Caso Herrera Ulloa, párr. 129.

61 Caso Ricardo Canese, párr. 103.

62 Ibídem, párr. 104. entre las restricciones que son aplicables cuando el objeto de la expresión se refiera a un particular y, por otro lado, cuando es una persona pública como, por ejemplo, un político" ${ }^{\prime \prime 5}$. Para la Corte "[e]l control democrático, por parte de la sociedad a través de la opinión pública, fomenta la transparencia de las actividades estatales y promueve la responsabilidad de los funcionarios sobre su gestión pública, razón por la cual debe existir un margen reducido a cualquier restricción del debate político o del debate sobre cuestiones de interés público ${ }^{\prime \prime 56}$.

Ya en aspectos más específicos sobre las restricciones, la Corte se hace cargo de un tema de mucha relevancia para el debate sobre la libertad de expresión y es cómo resolver el conflicto cuando este derecho entra en colisión con el derecho al honor de las personas. De conformidad con el artículo 11 de la Convención Americana toda persona tiene derecho al respeto de su honra y al reconocimiento de su dignidad, de forma tal que este derecho implica un límite a la expresión, ataques o injerencias de los particulares y del Estado. De ahí que sea perfectamente legítimo que quien se sienta afectado en su honor recurra a los mecanismos judiciales que el Estado disponga para su protección ${ }^{57}$. En este sentido, la Corte ha dicho que, si bien los funcionarios públicos deben estar expuestos a un mayor escrutinio de sus acciones, ello no implica

"de modo alguno, que el honor de los funcionarios públicos o de las personas públicas no deba ser jurídicamente protegido, sino que éste debe serlo de manera acorde con los principios del pluralismo democrático. Asimismo, la protección de la reputación de particulares que se encuentran inmiscuidos en actividades de interés público también se deberá realizar de conformidad con los principios del pluralismo democrático ${ }^{\prime 158}$.

Aclarado lo anterior y siguiendo los parámetros fijados por la Corte Europe $^{59}$, la Corte Interamericana ha señalado que "tratándose de funcionarios públicos, de personas que ejercen funciones de una naturaleza pública y de políticos, se debe aplicar un umbral diferente de protección, el cual no se asienta en la calidad del sujeto, sino en el carácter de interés público que conllevan las actividades o actuaciones de una persona determinada". Funda este trato particular en que las personas "que influyen en cuestiones de interés público se han expuesto voluntariamente a un escrutinio público más exigente $y$, consecuentemente, en ese ámbito se ven sometidos a un mayor riesgo de sufrir críticas, ya que sus actividades salen del dominio de la esfera privada para insertarse en la esfera del debate público"${ }^{\prime \prime 60}$. De esta forma, será la actividad la que determinará el escrutinio, razón por la cual, incluso privados que desarrollen actividades de interés público deberán estar sujetos a este mayor escrutinio ${ }^{61}$.

Con base en estas consideraciones, a juicio de la Corte, en este tipo de casos debe determinarse si la aplicación de responsabilidades penales ulteriores respecto de un supuesto ejercicio abusivo del derecho a la libertad de expresión, puede considerarse que cumple con el requisito de necesariedad en una sociedad democrática ${ }^{62}$. A su juicio, en estos 
casos es necesario "ponderar el respeto a los derechos o a la reputación de los demás con el valor que tiene en una sociedad democrática el debate abierto sobre temas de interés o preocupación pública"63.

Si bien la Corte formula estas apreciaciones en el Caso Canese, al momento de decidir no tuvo en consideración el conflicto de derechos planteado, sino que resolvió por la vía de considerar que la sanción impuesta como "medida ulterior de responsabilidad" había sido excesiva y por tanto, ella se constituía en una violación al artículo 13 de la CADH al no corresponder a una sanción proporcional ${ }^{64}$.

En el Caso Herrera Ulloa, habiendo hecho un razonamiento similar en términos de reconocer la necesidad de proteger el honor de los funcionarios, consideró violado el artículo 13 de la Convención toda vez que la restricción impuesta, al establecer requisitos muy rígidos para hacer operativa la exceptio veritatis ${ }^{65}$, implicaban un tipo de restricción que excede aquellas compatibles con el Pacto de San José.

\section{Derecho a un Recurso en Proceso Penal}

\section{Obligaciones del Estado}

Conforme lo dispuesto en los artículos 8.2.h) de la CADH y 14.5 del Pacto Internacional de Derechos Civiles y Políticos, en los juicios criminales existe el derecho para el inculpado de recurrir del fallo ante un tribunal superior, garantía que se aplica a todo juicio criminal, por pequeña que sea su envergadura. La disposición exige, entonces, que el ordenamiento jurídico nacional establezca un recurso contra el fallo de primera instancia, el que debe ser conocido por un tribunal superior, es decir, de mayor jerarquía. La disposición es también aplicable respecto de juicios criminales que tengan procedimientos especiales, como, por ejemplo, juicios de que conoce en primera instancia un tribunal superior como consecuencia del fuero personal del acusado.

En el caso Castillo Petruzzi y otros, la Corte sostuvo que el derecho a recurrir del fallo exigía que el tribunal superior "reúna las características jurisdiccionales que lo legitiman para conocer del caso concreto", lo que no sucedía en el caso por tratarse de un tribunal de segunda instancia que formaba parte de la estructura militar y, por lo tanto, no tenía la independencia necesaria ni constituía el "juez natural" que debía conocer de la revisión ${ }^{66}$.

Un recurso puede implicar la revisión completa de los hechos y el derecho, o puede implicar una revisión de la aplicación de las normas que evalúan la prueba y de las normas substantivas, o puede consistir en una revisión del derecho, pero limitada a ciertos aspectos del proceso. Es éste un punto delicado de resolver, porque hay que tener en consideración que una de las garantías del acusado consiste en que las pruebas se presenten en un juicio público, ante la presencia del juez, y que el principio de inmediación, que permite al juez formarse una impresión propia de las pruebas, es un aspecto
63 Ibídem, párr. 105.

64 Ibídem, párrs. 107 y 108. El sr. Canese fue condenado civil y penalmente y se le impusieron restricciones para salir del país durante ocho años y casi cuatro meses.

${ }^{65}$ Caso Herrera Ulloa, párrs. 132-135.

${ }^{66}$ Caso Castillo Petruzzi y otros, párr. 161. 
${ }^{67}$ C. Medina y C. Nash, "Manual de Derecho Internacional de los Derechos Humanos para Defensores Públicos. Sección doctrina", en Documentos Oficiales, Centro de

Documentación Defensoría Penal Pública, $N^{\circ} 1$, diciembre 2003.

${ }^{68}$ Caso Herrera Ulloa, párr. 158.

69 Ibídem, párr. 159. Sobre la unidad del proceso penal, ver Caso Castillo Petruzzi y otros, párr. 161.

${ }^{70}$ Caso Herrera Ulloa, párr. 161. En el mismo sentido, ver Caso Baena Ricardo y otros, párr. 77; Caso Maritza Urrutia, párr. 117; y Caso Juan Humberto Sánchez, párr. 121.

71 Caso Herrera Ulloa, párr. 163.

72 Ibídem, párr. 164. importante de confiabilidad de las bases fácticas en que se funda la sentencia ${ }^{67}$.

\section{Jurisprudencia Relevante}

En el Caso Herrera Ulloa la Corte tuvo oportunidad para pronunciarse sobre los alcances del derecho establecido en el artículo 8.2.h) de la Convención Americana.

La Corte señala que este derecho permite que "una sentencia adversa pueda ser revisada por un juez o tribunal distinto y de superior jerarquía orgánica" y "busca proteger el derecho de defensa otorgando durante el proceso la posibilidad de interponer un recurso para evitar que quede firme una decisión que fue adoptada con vicios y que contiene errores que ocasionarán un perjuicio indebido a los intereses de una persona $^{\prime \prime 68}$. De esta forma, la Corte ha interpretado este derecho en un sentido amplio, entendiendo que este derecho está vinculado tanto con los vicios de una decisión penal, como los errores que pudieran ocasionar perjuicio a los intereses de una persona.

Siguiendo con la idea de la efectividad de los derechos consagrados por la Convención, la Corte señala que este derecho "no se satisface con la mera existencia de un órgano de grado superior al que juzgó y condenó al inculpado, ante el que éste tenga o pueda tener acceso", sino que "es preciso que el tribunal superior reúna las características jurisdiccionales que lo legitiman para conocer del caso concreto"; todo ello en el entendido que "el proceso penal es uno solo a través de sus diversas etapas, incluyendo la tramitación de los recursos ordinarios que se interpongan contra la sentencia" ${ }^{\prime 69}$.

Pasa luego la Corte a señalar cuáles son los criterios que nos permiten conocer si un recurso es eficaz. El recurso "debe ser un recurso ordinario eficaz mediante el cual un juez o tribunal superior procure la corrección de decisiones jurisdiccionales contrarias al derecho". Al respecto, la Corte reconoce que "Ios Estados tienen un margen de apreciación para regular el ejercicio de ese recurso", pero estos "no pueden establecer restricciones o requisitos que infrinjan la esencia misma del derecho de recurrir del fallo", de forma tal que "no basta con la existencia formal de los recursos sino que éstos deben ser eficaces, es decir, deben dar resultados o respuestas al fin para el cual fueron concebidos" ${ }^{\prime 70}$.

Sobre la función del tribunal o juez superior que debe conocer del recurso, la Corte ha señalado que "tiene el deber especial de protección de las garantías judiciales y el debido proceso a todas las partes que intervienen en el proceso penal de conformidad con los principios que lo rigen ${ }^{\prime 71}$. En lo procesal, la posibilidad de acceder al recurso "debe ser accesible, sin requerir mayores complejidades que tornen ilusorio este derecho" ${ }^{\prime 72}$.

En lo que nos parece el mayor aporte para el análisis de los recursos internos, la Corte ha señalado cuál es el criterio básico que debe cumplir 
un recurso penal para ser compatible con la Convención: "lo importante es que dicho recurso garantice un examen integral de la decisión recurrida" ${ }^{\prime 73}$. En este sentido, refiriéndose en concreto al caso en estudio, pero a través de esto fijando los alcances de su interpretación acerca del derecho en cuestión, la Corte considera que no satisface el derecho a un recurso si la legislación interna no permite "que el tribunal superior realizara un análisis o examen comprensivo e integral de todas las cuestiones debatidas y analizadas en el tribunal inferior ${ }^{\prime 74}$.

De esta forma, la Corte ha entendido este recurso en forma amplia, lo que parece no adecuarse con los estándares restrictivos de nuestra nueva legislación procesal penal en materia de recursos. Esta situación debiera exigir una revisión de nuestra legislación antes de vernos expuestos a una sentencia condenatoria en el sistema internacional ${ }^{75}$.

\section{Opiniones consultivas citadas}

La Colegiación Obligatoria de Periodistas (arts. 13 y 29 Convención Americana sobre Derechos Humanos). Opinión Consultiva OC-5/85 del 13 de noviembre de 1985. Serie A No. 5.

Condición Jurídica y Derechos Humanos del Niño. Opinión Consultiva OC-17/02 de 28 de agosto de 2002. Serie A No. 17.

\section{Sentencias definitivas citadas}

Caso Loayza Tamayo. Sentencia de 17 de septiembre de 1997. Serie C No. 33.

Caso Castillo Petruzzi y otros. Sentencia de 30 de mayo de 1999. Serie C No. 52.

Caso de los "Niños de la Calle" (Villagrán Morales y otros). Sentencia de 19 de noviembre de 1999. Serie C No. 63.

Caso Cantoral Benavides. Sentencia de 18 de agosto de 2000. Serie C No. 69.

Caso Baena Ricardo y otros. Sentencia de 2 de febrero de 2001. Serie C No. 72.

Caso "La Última Tentación de Cristo" (Olmedo Bustos y otros). Sentencia de 5 de febrero de 2001. Serie C No. 73.

Caso Ivcher Bronstein. Sentencia de 6 de febrero de 2001. Serie C No. 74.

Caso "Cinco Pensionistas". Sentencia de 28 de febrero de 2003. Serie C No. 98.

Caso Juan Humberto Sánchez. Sentencia de 7 de junio de 2003. Serie C No. 99.

Caso Bulacio. Sentencia de 18 de septiembre de 2003. Serie C No. 100.
73 Ibídem, párr. 165.

74 Ibídem, párr. 167 (itálicas nuestras).

75 Una opinión sobre la compatibilidad de la legislación nacional con la internacional en esta materia, ver Horvitz, M. y López, J., Derecho Procesal Penal Chileno, Editorial Jurídica de Chile, 2002, pp. 354-363. 
Caso Maritza Urrutia. Sentencia de 27 de noviembre de 2003. Serie C No. 103.

Caso Herrera Ulloa. Sentencia de 2 de julio de 2004. Serie C No. 107.

Caso de los Hermanos Gómez Paquiyauri. Sentencia de 8 de julio de 2004. Serie C No. 110.

Caso Ricardo Canese. Sentencia de 31 de agosto de 2004. Serie C No. 111.

Caso "Instituto de Reeducación del Menor". Sentencia de 2 de septiembre de 2004. Serie C No. 112.

Caso Tibi. Sentencia de 7 de septiembre de 2004. Serie C No. 114.

Caso Lori Berenson Mejía Vs. Perú. Sentencia de 25 de noviembre de 2004. Serie C No. 119. 